\title{
Modification of Attentional Bias to Emotional Faces Following Mindfulness-Based Cognitive Therapy in People with a Current Depression
}

\author{
Paweł Holas $^{1}$ • Izabela Krejtz ${ }^{2}$ - Katarzyna Wisiecka ${ }^{2}$ - Marzena Rusanowska ${ }^{3}$ - John B. Nezlek ${ }^{4,5}$
}

Published online: 19 March 2020

(C) The Author(s) 2020

\begin{abstract}
Objectives Mindfulness-based cognitive therapy (MBCT) is an evidence-based treatment to prevent relapse in individuals with recurrent major depressive disorder (MDD). It is not clear if MBCT is an effective therapy for current depression, and it is not clear what mechanisms are responsible for the effectiveness of MBCT. Theoretically, MBCT is believed to modify the processing of emotional information and reduce cognitive vulnerability to depression; however, it is not clear if MBCT leads to normalization of attentional biases in depressed individuals. The aim of the current study was to determine if MBCT can modify some of the attentional biases underlying depression in MDD.

Methods Participants were 53 individuals with diagnosis of current MDD. They were randomly assigned to either MBCT $(n=$ $25)$ or wait list control group $(n=28)$ condition. Before and after the 8 -week MBCT intervention participants completed the Center for Epidemiological Studies Depression scale (CESD), they viewed slides presenting sad, angry, happy, and neutral facial expressions, and their eye movements were recorded during the viewing task.

Results As expected, compared to participants in the control group, the CESD scores of participants who received MBCT decreased following treatment, their attention to sad faces decreased, and their attention to happy faces increased. Moreover, cross-lagged analysis suggested a causal link from changes in attentional bias to changes in depression.

Conclusions We found that MBCT can modify the attentional processing of emotional facial stimuli and that attentional bias modification may translate into clinical improvement in currently depressed individuals.
\end{abstract}

Keywords Mindfulness-based cognitive therapy $\cdot$ Attention $\cdot$ Emotion $\cdot$ Eye-tracking $\cdot$ Depression

Electronic supplementary material The online version of this article (https://doi.org/10.1007/s12671-020-01353-2) contains supplementary material, which is available to authorized users.

Paweł Holas

pawel.holas@psych.uw.edu.pl

1 Faculty of Psychology, University of Warsaw, ul. Stawki 5/7, 00-183 Warsaw, Poland

2 Psychology Department, SWPS University of Social Sciences and Humanities, Warsaw, Poland

3 Institute of Psychology, Polish Academy of Sciences, Warsaw, Poland

4 Institute of Psychology, SWPS University of Social Sciences and Humanities, Poznan, Poland

5 Department of Psychology, College of William \& Mary, Williamsburg, VA, USA
Major depressive disorder (MDD) is one of the most common and burdensome psychiatric disorders with a lifetime prevalence rate of approximately 16\% (Kessler et al. 2009). According to the World Health Organization, MDD is currently the leading cause of disability worldwide (World Health Organization 2017). Although many treatments have been proposed (Dimidjian et al. 2006), many of them have been found to have limited efficacy (Cuijpers et al. 2010), particularly in terms of preventing relapse.

MDD has a high relapse rate or recurrence after remission or recovery (Kessler et al. 2003). Up to $80 \%$ of individuals with a history of two episodes are likely to have another recurrence (Kupfer et al. 1996). Mindfulness-based cognitive therapy (MBCT) was developed to reduce the risk of depressive relapse by attenuating the reactivation of dysfunctional thinking styles that represent one of the core mechanism by which CBT prevents depressive relapse (Segal et al. 2002). MBCT blends elements of cognitive behavioral therapy for 
depression (Teasdale et al. 2000) with mindfulness training (Segal et al. 2002), and MBCT has been found to reduce relapse in patients with recurrent MDD, defined as 3 or more previous episodes (e.g., Godfrin and van Heeringen 2010; Ma and Teasdale 2004; Teasdale et al. 2000). For a similar conclusion, see meta-analyses by Piet and Hougaard (2011) and Kuyken et al. (2016). Based on this evidence, MBCT has been recommended as a prophylactic treatment for recurrent MDD (i.e., National Institute for Clinical Excellence 2009); howev$\mathrm{er}$, it is not clear if MBCT is effective in treating current MDD. Interestingly, despite the fact that MBCT was developed to prevent the recurrence of depression, patients who were currently depressed were excluded from the first seminal studies (Teasdale et al. 2000; Ma and Teasdale 2004).

Several researchers have raised concerns that depressive symptoms such as difficulty with concentration and intensity of negative thinking that may preclude the acquisition of attention regulation skills that are essential to MBCT (e.g., Segal et al. 2002). Regardless, a growing body of research has found that MBCT can reduce depressive symptoms per se (Finucane and Mercer 2006; Kenny and Williams 2007). Recently, several attempts have been made to use MBCT to treat the currently depressed (e.g., Van Aalderen et al. 2012), and this research suggests that MBCT could also be an effective treatment for current depression (Goldberg et al. 2018; Strauss et al. 2014).

MBCT was designed to target the cognitive reactivity (Segal et al. 2002), e.g., the ease with which dysphoric mood can reactivate constellation of negative thoughts and feelings that may lead to a depressive episode. Several laboratory studies have found that cognitive reactivity is a marker for vulnerability to relapse and recurrence of depression (Lau et al. 2004). For example, Segal et al. (2006) found that recovered depressed individuals tended to decline into depressogenic thinking patterns following the induction of sad moods, and those who exhibited greater reactivation of dysfunctional thinking styles in response to the sad mood induction were at the greatest risk of relapse over the following 18 months. Importantly for the current study, research has also found that attentional bias for sad faces is associated with significantly greater impairments in mood recovery following mood induction among individuals with MDD than it is among nonclinical subjects (Clasen et al. 2013). These findings suggest that change in depressive attentional bias may be linked to mechanisms that are the focus of MBCT.

Cognitive theories assume that attentional biases to negative emotional stimuli play important roles in the development and maintenance of depression (e.g., Clark and Beck 1999; Williams et al. 1988), and this assumption has been supported by a wealth of research (Armstrong and Olatunji 2012; Foland-Ross and Gotlib 2012). For example, eye tracking studies have consistently found that depression is associated with prolonged maintenance of gaze on negative information
(Caseras et al. 2007; Eizenman et al. 2003; Kellough et al. 2009), and greater neglect of positive information (e.g., De Raedt and Koster 2010, see Peckham et al. 2010). Prolonged processing of negative information leads to more persistent sad mood (e.g., Disner et al. 2017) and has been found to be related to greater trait rumination (Donaldson et al. 2007; Owens and Gibb 2017) and increased daily rumination in depressed individuals (Holas et al. 2019).

"Mindfulness is defined as awareness that emerges through paying attention on purpose, in the present moment, and nonjudgmentally to the unfolding of experience moment by moment" (Kabat-Zinn 2003, p. 145). Mindfulness thus involves awareness of the direction of attention and the ability to switch attention between thoughts, feelings, or bodily sensations and present stimuli (Bishop et al. 2004). Learning to stabilize attention through mindfulness exercises could be a way for people to recognize their cognitive reactivity and provide a basis for decentering and avoiding negative patterns of thinking (Williams and Kabat-Zinn 2011). In MBCT, this is achieved by instructing people to redirect their attention to the present moment, usually their own breathing. In turn, this can increase the voluntary deployment of attention (Segal et al. 2002).

Research on MBCT has found that decreases in dysfunctional thinking (rumination and worry) mediated treatment outcomes and relationships between cognitive reactivity and relapse risk (for meta-analysis see Gu et al. 2015 and van der Velden et al. 2015). Nevertheless, modifying attention to emotional stimuli as a therapeutic mechanism of MBCT as a treatment for current depression has not been examined that thoroughly (Alsubaie et al. 2017). Biases in attentional processing are a hallmark characteristic of depression and a vulnerability factor of depression (Joormann and Gotlib 2007; Koster et al. 2011), and so research on modifying attention within the confines of MBCT is clearly warranted.

Some research has been done on the impact of mindfulness training on attentional processes. This research has focused on processing at the level of specific components of attention (alerting, orienting, and executive attention), general attentional processing following short-term (like MBCT), and long-term meditation training in healthy participants (e.g., Anderson et al. 2007; Chambers et al. 2008; Chan and Woollacott 2007; Jha et al. 2007; Moore and Malinowski 2009; Slagter et al. 2007; Van den Hurk et al. 2010). Only a few studies have examined the effects of MBCT on attention in clinically depressed patients (e.g., De Raedt et al. 2012; Van den Hurk et al. 2012; Verhoeven et al. 2014). In addition, recent research suggests that mindful attention can lead to decentering by disengaging the self from imagined situations so that negative affective reactions do not develop (Lebois et al. 2015).

To our knowledge, only two published studies have evaluated changes in attentional biases to emotional information following MBCT (De Raedt et al. 2012; Verhoeven et al. 
2014). These studies examined attentional processes in people who were formerly depressed but were in remission, and they measured reaction times manually. The majority of research on attentional biases in emotional disorders has measured attention using reaction time (RT) (e.g., Bar-Haim et al. 2007 for meta-analysis).

Although studies using RT to measure attention are informative, as discussed by Armstrong and Olatunji (2012), RTbased measures of attention are limited in potentially significant ways. For example, when measuring attention using RT, there is a possible confound between the effects of a stimulus and the time it takes to press a key to record a response. Another limitation is that RT is based on measures of individual points in time ("a snapshot"), which makes it problematic to capture the dynamics of attention.

Eye tracking is an alternative to RT that measures attention dynamically and provides accurate measures for assessing the time course of visual attention with no delay between attending to a stimulus and the measurement of attention. Because of these advantages, the use of eye-tracking to measure attention in studies of relationships between attentional processes and emotions has increased in recent years (e.g., Armstrong and Olatunji 2012). Given these advantages, in the present research, we measured attentional processes using eye-tracking.

The aims of the current study were to determine if MBCT can reduce depressive symptoms and if it can modify attentional biases to negative information underlying depression in currently depressed individuals. In addition, we wanted to examine possible causal relationships between the severity of depressive symptoms severity and attentional biases. We expected that MBCT would reduce depressive symptoms in MDD individuals and lead to normalization of attentional biases. Specifically, we expected a reduced attention (gaze duration) to sad and angry faces, and increased gaze duration to happy faces after MBCT, and no such effects in our control group. Furthermore, we hypothesized that modification of attentional bias to negative faces precludes decrease in depressive scores. We expected therefore, that gaze duration at pre-test would be related to CESD scores at post-test but that CESD scores at pre-test would not be related to gaze duration at post-test.

\section{Method}

\section{Participants}

Participants were recruited via open calls posted on popular Internet portals. The calls invited people to participate in a study that involved MBCT training for 8 weeks and concerned how people feel and how they process information in their daily lives. A total of 692 people completed an online screening that consisted of background data and the Center for Epidemiological Studies Depression scale (CESD, Radloff
1977). A total of 249 individuals were excluded on the basis following criteria: their CESD scores were below $20(n=66)$, or that they were younger than $25(n=150)$ or that they were taking psychiatric medications $(n=73)$ (some of them had multiply criteria). We then phone interviewed 273 people in order to qualify them in terms of 2 major criteria for depression (sadness or anhedonia for at least 2 weeks) to establish higher likelihood of meeting DSM criteria for current major depressive episode. Based on the phone interview, 154 people were excluded if they were currently receiving psychotherapy $(n=14)$; if they were suffering from a current or lifetime psychotic disorder, bipolar disorder, substance abuse problem; if they reported current suicidal tendencies $(n=15)$; or if they did not meet criteria for major depression $(n=63)$. Sixty-two were not interested in participation. We qualified 119 people who were then invited for a clinical interview in the laboratory. A total of 84 people came to a structured clinical interview (the Mini-International Neuropsychiatric Interview (MINI) version 5.0.0; Sheehan et al. 1998) conducted by a trained clinician. Three people were excluded from the study because they had comorbid diagnoses based on the MINI. Details how the subjects flowed through the study are presented in the CONSORT flow chart (Fig. 1).

The final sample consisted of 81 participants meeting DSMIV criteria for MDD. In terms of ethnicity, all participants were white, which was not unusual given the demographics of the country in which the study was conducted. Participants were assigned to either MBCT group or wait list control condition. Twenty-four participants dropped out of the study after the pretesting. The final sample consisted of 25 participants in the MBCT group (20 Female, $\left.M_{\text {age }}=34.96, S D=8.01\right)$ and 28 in control condition (19 Female, $M_{\text {age }}=34.25, S D=8.75$ ). The groups did not differ in terms of mean age and gender $(p s=.76$, .32 , respectively). Summary statistics of previous episodes of depression and of comorbidity are presented in Table 1.

\section{Procedure}

The study consisted of the following components: a laboratory session during which participants performed the eye-tracking task, followed by the maintenance of an online diary for 7 consecutive days (these data are not relevant to the current hypotheses and are not discussed in this paper), 8 weeks of MBCT training for experimental group or a waiting period for the control group, the maintenance of an online diary for 7 consecutive days (these data are not relevant to the current hypotheses and are not discussed in this paper), and then followed by a laboratory session during which post-training measures were collected, including the eye tracking task and the CESD.

Eye Tracking Task Four-face task. In this task, based on Leyman et al. (2011), a series of 12 slides with four facial expressions (neutral, sad, angry, and happy) was shown to 


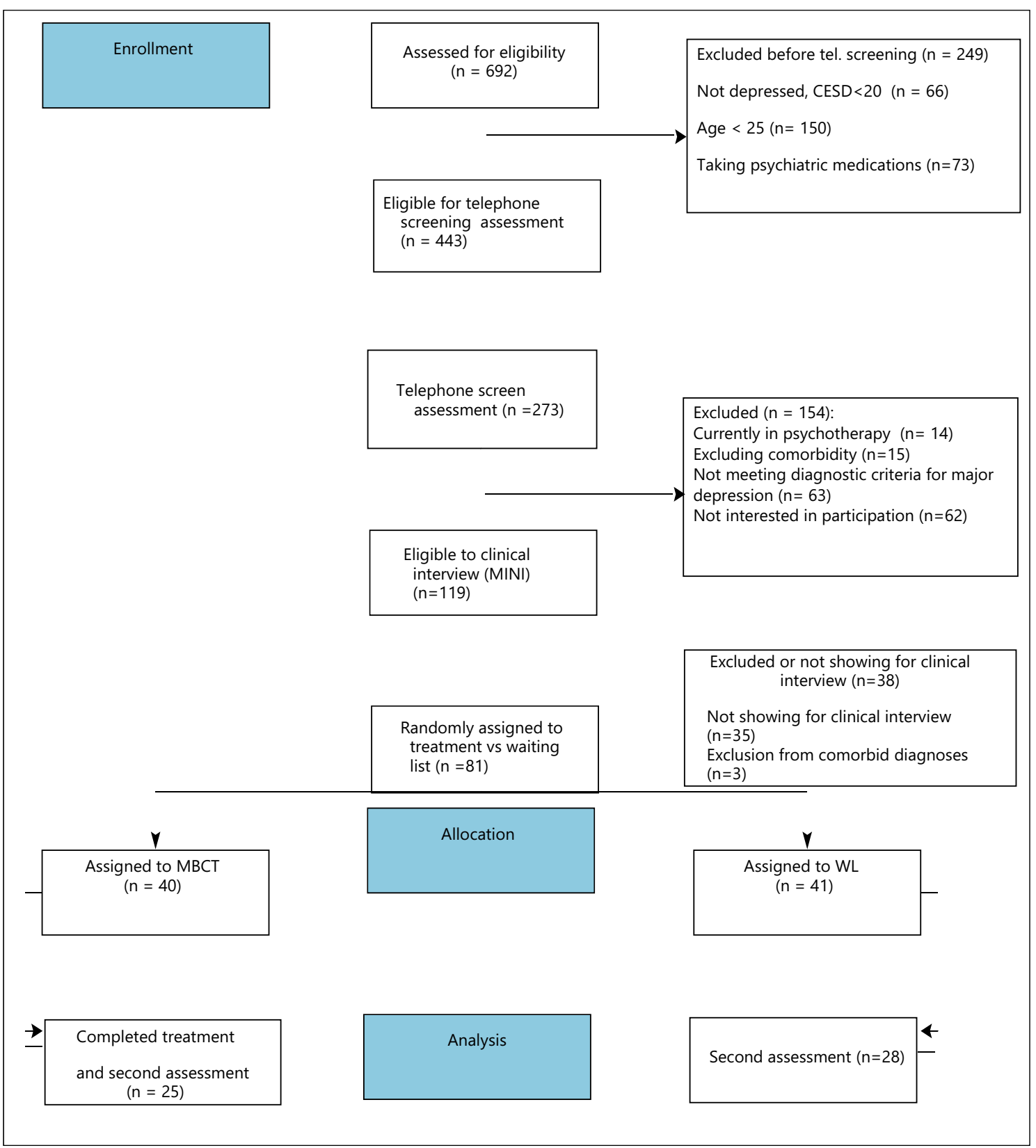

Fig. 1 Consort diagram: enrollment and study flow

participants. We used expressions of 6 female and 6 male faces taken from the Karolinska Directed Emotional Faces database (Goeleven et al. 2008). The four facial expressions of the same model were simultaneously presented for $10 \mathrm{~s}$ in one of 4 quadrants of the slide on a black background (see Fig. 2). The positions of expressions within each slide were randomized and fixed for all participants, and the order of the slides was random for each participant. Each trial began with a fixation cross in the middle of the screen for $1000 \mathrm{~ms}$. Participants were told to look at each of the slides.

Intervention We used a MBCT protocol developed by Segal et al. (2002). It consisted of 8 weekly sessions of $2.5 \mathrm{~h}$ each, with a 5 -h day-long retreat between the 6th and 7th sessions. The MBCT training was provided by two trainers with extensive experience in meditation and MBCT. One was a psychiatrist and cognitive behavioral therapist with 8 years of experience guiding MBCT and MBSR groups. The second was a psychologist with 8 years of mindfulness-based intervention experience. Training groups consisted of up to 16 participants.

\section{Measures}

Eye Tracking Presentation of the stimuli was controlled by SMI Experiment Center software with an eye-tracking device. The stimuli were presented on a $19^{\prime}$ monitor at a resolution of 
Table 1 Description of previous episodes of depression and comorbidities

\begin{tabular}{lll}
\hline & MBCT, $N=25$ & Control, $N=28$ \\
\hline Age of first episode & $\begin{array}{l}N=19, M=23.5 \\
(\mathrm{SD}=8), \text { range }=\end{array}$ & $\begin{array}{l}N=24, M=23 \\
(\mathrm{SD}=9), \text { range } \\
12-41\end{array}$ \\
$\begin{array}{ll}12-42 \\
\text { Previous episodes }\end{array}$ & & \\
1 & 1 & 2 \\
$2-5$ & 7 & 14 \\
$>5$ & 17 & 12 \\
Diagnoses & & \\
1 additional diagnosis & $5(20 \%)$ & $7(25 \%)$ \\
2 or more additional & $10(40 \%)$ & $12(43 \%)$ \\
diagnoses & & 1 \\
Dysthymia & 5 & 12 \\
GAD & 5 & 6 \\
Social phobia & 8 & 2 \\
Panic attacks & 3 & 3 \\
Specific phobia & 2 & 3 \\
OCD & 2 & 0 \\
Agoraphobia & 3 & \\
\hline
\end{tabular}

$1680 \times 1050$. Participants' eye movements were recorded with SMI RED $120 \mathrm{~Hz}$ eye tracker, with a conventional 9point calibration before each task. BeGaze SMI software was used to calculate standard eye movement indices. Fixations were defined as stable eye movements, within 1 degree of visual angle, lasting for at least $100 \mathrm{~ms}$. Areas of interest were drawn around each face in each trial. For each of the face, the total gaze duration (GD), the dwell time spent fixating on the face, was calculated.

Self-Report of Depressive Symptoms Before and after training, participants completed the Center for Epidemiological Studies Depression Scale (Radloff 1977). The CESD is a 20-item scale measuring symptoms of depression. Using a 4-point scale, with end points anchored 0 (rarely or none of the time, less than 1 day) and 3 (most of the time, 5-7 days) participants reported how often they experienced each of the symptoms during the previous week. The reliabilities for the scale were satisfactory at both pre- and post-testing ( $\alpha \mathrm{s}=.82$ and .94 respectively).

Copies of all measures and the raw data are available at: https://osf.io/dq64j/

\section{Data Analysis}

Recording eye movements during the four-face task allowed us to examine if MBCT training modified participants' attention to positive and negative faces. Our general expectation was that MBCT training would lead to a reduction of gaze toward negative faces and an increase in gaze duration to positive faces. We carried out a series of $2 \times 2 \times 4$ mixed ANOVAs with training (MBCT vs. control) as a betweensubject factor, testing session (pre-training vs. post-training) and face type (angry vs. happy vs. neutral vs. sad) as withinsubject factors.
Fig. 2 An example of the four facial expressions of the same model in the four-face task

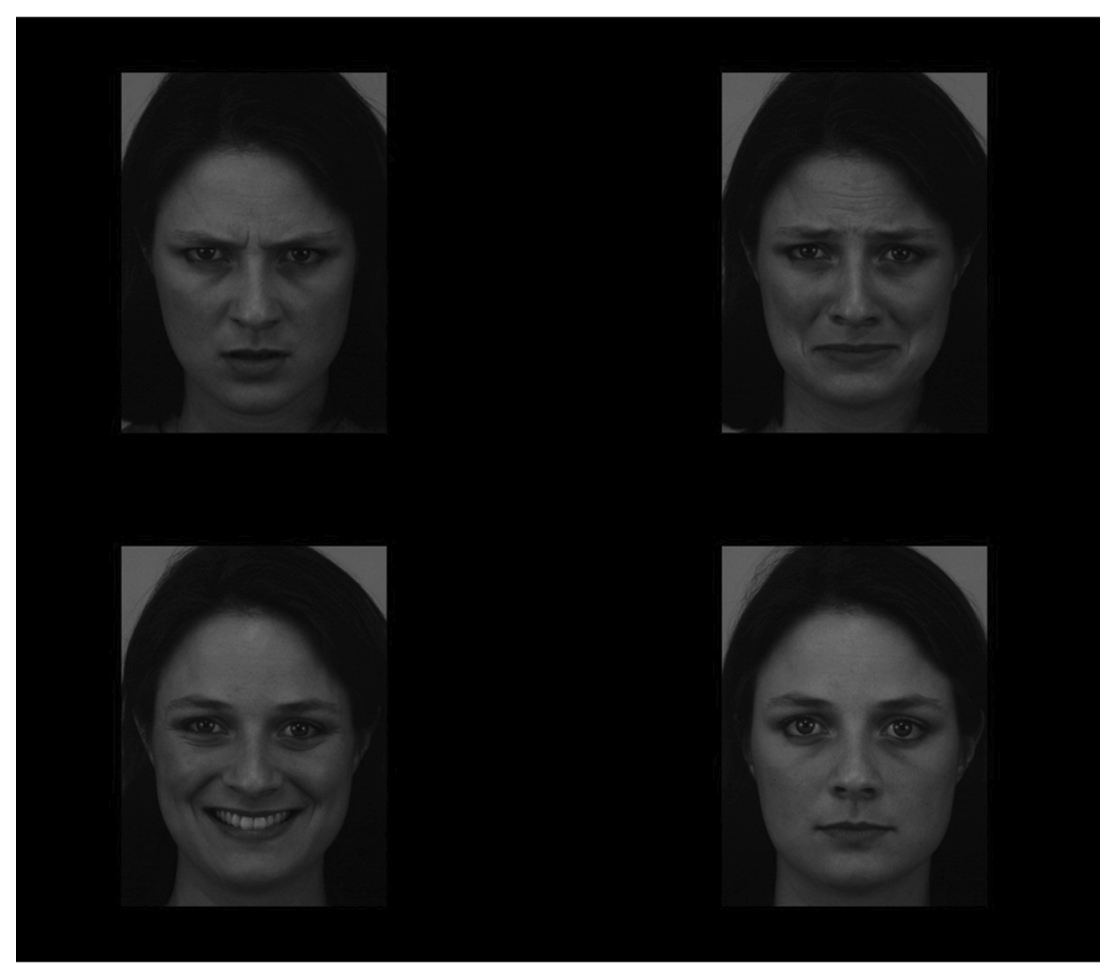


We also expected to find significant reduction in depression symptoms. We examined such changes using a $2 \times 2$ ANOVA with training (MBCT vs. control) as a between-subject factor and testing session (pre-training vs. post-training) as a withinsubject factor. When appropriate, post-hoc tests of differences were performed using Bonferroni correction, and the results are reported with Greenhouse-Geisser correction whenever the sphericity assumption was violated.

Finally, we tested cross-lagged relationships between gaze duration and depressive symptoms. We examined if relative gaze duration at pre-training session predicted depressive symptoms measured at time post-training and if depressive symptoms at pre-training predicted relative gaze duration at the post-training. If one such lagged relationship is significant and the other is not, this suggests that one construct is a cause and the other is an effect. We expected that gaze duration at pre-test would be related to CESD scores at post-test but that CESD scores at pre-test would not be related to gaze duration at post-test.

\section{Results}

\section{Eye-Tracking Measures of Focus on Emotional Facial Expressions}

We measured visual attention using gaze duration (i.e., how long, in total, a person dwelled on a face) separately for angry, happy, neutral, and sad faces. Before the analyses, we examined distributions of raw gaze durations. As a result, we excluded the data from five participants from the analyses. The mean gaze durations of two participants from the MBCT group and two participants from the control group were $3 S D$ or more above their group's mean, and the mean gaze duration of one participant from the control group was $3 S D$ below the group mean.

Similar to Owens and Gibb (2017) and Krejtz et al. (2018), we measured attentional bias by calculating gaze duration for specific facial expressions controlling for total gaze duration for all facial expressions. We used the relative score not an absolute gaze duration because it is a more direct measure of an attentional bias reflecting the difference between processing of happy, sad, angry, and neutral faces, and it is currently the standard procedure in studying attentional biases. We calculated relative scores for each of the facial expressions using a standard formula (e.g., Everaert et al. 2014; Owens and Gibb 2017). The total gaze duration for each type of face (target face in the formula below) was divided by the total viewing time for all facial expressions.

$\mathrm{GD}_{\text {relative }}=\frac{\text { Gaze Duration }}{\text { target face }}$
This adjusted the gaze duration for a specific type of face for total of gaze durations on all four types of faces. A score of .25 indicates equal gaze distribution between the target face and other faces, scores above .25 indicate a preference for the target face (longer total viewing time), and scores below .25 indicate less attention toward the target face relative to other facial expressions.

\section{Relative Gaze Duration}

Descriptive statistics for gaze duration and relative gaze are presented in Table 2. We should note that analyses of absolute gaze duration produced results that were functionally equivalent to analyses of relative gaze duration. We present the results of analyses of relative gaze duration because the relative measure is reported more often than the absolute measure.

The analyses of relative gaze duration produced a significant interaction effect among training, testing session, and face type $\left(F_{(3,138)}=4.02, p=.009, \eta_{\mathrm{p}}{ }^{2}=.08\right)$. This interaction can be understood in two ways (see Table 2). First, the interaction can be interpreted as a result of the fact that for participants in the MBCT group the relative gaze time at happy faces significantly increased from pre- to post-training $\left(F_{(1}\right.$, 46) $\left.=13.36, p<.001, \eta_{\mathrm{p}}{ }^{2}=.225\right)$, whereas the relative time spent looking at sad and angry faces significantly decreased from pre- to post-training $\left(F_{(1,46)}=4.79, p=.034, \eta_{\mathrm{p}}{ }^{2}=.094\right.$; $F_{(1,46)}=7.35 p=.009, \eta_{\mathrm{p}}{ }^{2}=.138$, respectively). In contrast, for the control group, there were no significant differences between pre- and post-training sessions for these measures $(p s>.5)$.

Alternatively, the interaction can be interpreted as the result of the fact that for the MBCT group, at the pre-training session, there were no significant differences between time spent on different faces $\left(F_{(3,44)}=1.05, p=.38\right)$, whereas there were significant differences at post-training $\left(F_{(3,44)}=10.51\right.$, $\left.p<.001, \eta_{\mathrm{p}}{ }^{2}=.417\right)$. After MBCT training, participants looked longer at happy faces compared to angry faces $(p<.001)$, sad faces $(p=.001)$, and neutral faces $(p=.02)$. They also gazed longer at neutral faces compared to angry faces $(p=.046)$, and sad faces $(i=.02)$. In contrast, participants in the control group looked longer at neutral than angry faces at both pre-test $\left(p=.009, F_{(3,44)}=4.13, p=.012\right.$, $\left.\eta_{\mathrm{p}}{ }^{2}=.220\right)$ and at post-test $\left(p<.001, F_{(3,44)}=8.62\right.$, $\left.p<.001, \eta_{\mathrm{p}}{ }^{2}=.37\right)$.

Finally, we compared group differences at the pre-post training sessions. At the pre-training session, there were no group differences in relative gaze duration on different faces (for angry: $F_{(1,46)}=2.14, p=.15, \eta_{\mathrm{p}}{ }^{2}=.044$, sad: $F_{(1,46)}<1$, happy: $F_{(1,46)}=1.46, p=.23, \eta_{\mathrm{p}}{ }^{2}=.031$, neutral: $F_{(1,46)}=$ $\left.3.58, p=.07, \eta_{\mathrm{p}}{ }^{2}=.072\right)$. At the post-training session, MBCT group looked significantly longer at happy faces $\left(F_{(1,46)}=\right.$ $\left.15.23, p<.001, \eta_{\mathrm{p}}{ }^{2}=.249\right)$ and significantly less at sad faces 
Table 2 Descriptive statistics for gaze duration and relative gaze duration depending on face type and group

\begin{tabular}{|c|c|c|c|c|}
\hline \multirow[b]{2}{*}{ Face type/group } & \multicolumn{2}{|l|}{ Gaze duration (ms) } & \multicolumn{2}{|c|}{ Relative gaze duration } \\
\hline & Pre-test mean (SE) & Post-test & Pre-test & Post-test \\
\hline \multicolumn{5}{|l|}{ Нарру } \\
\hline MBCT & $2243.25(147.90)$ & $2965.22(220.75)$ & $.274(.015)$ & $.349(.017)$ \\
\hline Control & $2065.04(139.75)$ & $2142.52(208.59)$ & $.250(.014)$ & $.254(.017)$ \\
\hline \multicolumn{5}{|l|}{ Sad } \\
\hline MBCT & $1981.24(96.21)$ & 1573.05 (117.20) & $.235(.009)$ & $.198(.012)$ \\
\hline Control & $1932.33(90.91)$ & 1901.27 (110.74) & $.243(.010)$ & $.250(.011)$ \\
\hline \multicolumn{5}{|l|}{ Angry } \\
\hline MBCT & $2059.63(114.45)$ & $1624.89(106.82)$ & $.239(.011)$ & $.207(.011)$ \\
\hline Control & $1730.12(108.15)$ & $1599.71(100.94)$ & $.217(.010)$ & $.214(.010)$ \\
\hline \multicolumn{5}{|l|}{ Neutral } \\
\hline MBCT & 2107.81 (139.67) & 2157.09 (139.81) & $.252(.015)$ & $.247(.008)$ \\
\hline Control & $2335.74(131.98)$ & $2184.23(132.10)$ & $.291(.014)$ & $.282(.008)$ \\
\hline
\end{tabular}

and neutral faces than participants in the control condition $\left(F_{(1,46)}=10.04, p=.003, \eta_{\mathrm{p}}{ }^{2}=.179 ; F_{(1,46)}=10.35\right.$, $p=.002, \eta_{\mathrm{p}}{ }^{2}=.184$; respectively).

\section{Other Effects}

These analyses also produced other significant effects (e.g., a main effect for face types). Given that these effects did neither test nor were they relevant to any of our hypotheses and many of the effects were qualified by the triple interaction, these effects are not described. They are presented in the online, supplemental materials.

\section{Depressive Symptoms}

The analysis of variance of CESD scores produced significant training $\times$ testing session interaction $(F(1,50)=10.04$, $\left.p=.003, \eta_{\mathrm{p}}{ }^{2}=.167\right)$. At the pre-training session, there was no significant difference between the MBCT and the control group $(M=43.00, S E=1.58, M=40.67, S E=1.52$, respectively; $\left.F(1,50)=1.14, p=.292, \eta_{\mathrm{p}}{ }^{2}=.022\right)$. In contrast, and as expected, at the post-training session the difference between the MBCT and the control group was statistically significant $\left(F(1,50)=8.61, p=.005, \eta_{\mathrm{p}}{ }^{2}=.147\right)$. The MBCT group had significantly lower CESD score $(M=18.52, S E=$ 2.43) than the control group $(M=28.41, S E=2.34)$.

\section{Cross-Lagged Analyses}

We examined possible causal relationships between depressive symptoms (CESD scores) and gaze duration using cross-lagged panel analyses. In these analyses, CESD scores at post-test were regressed on gaze duration at pre-test, while simultaneously, gaze duration at post-test was regressed on CESD scores at pre-test. The logic of these analyses is that temporal precedence is a necessary (although not sufficient) condition for causes: Causes precede effects. A causal link from gaze duration to depression would be suggested by a significant relationship between duration at pre-test and CESD scores at post-test, whereas a causal link from depression to gaze duration would be suggested by a significant relationship between CESD scores at pre-test and duration at post-test.

These analyses were limited to participants in the MBCT condition, and each measure of gaze duration was analyzed separately. The analyses were conducted using MPlus (Muthén and Muthén 1998-2012), and the model used for these analyses is presented in Fig. 3. As can be seen from this figure, each post-test measure was regressed on both pre-test measures, and the error covariances between the two measures at pre-test and at post-test were modeled.

The lagged coefficients from these analyses are summarized in Table 3. As can be seen from these coefficients, the lags from duration of gaze on sad faces to CED scores and from duration of gaze on happy faces to CESD scores were significant. In contrast, neither of the lags from CESD scores to gaze duration on sad faces and on happy faces was significant. Such a pattern of results is consistent with a casual sequence in which changes in attentional focus lead to

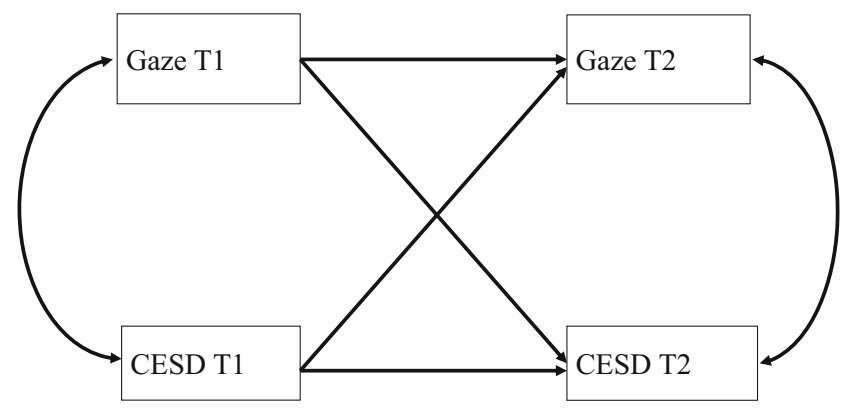

Fig. 3 The model used for cross-lagged analyses 
Table 3 Lagged relationships between depression and relative gaze to emotional expressions

\begin{tabular}{llcll}
\hline Time 1 & Time 2 & Coeff. & $\begin{array}{l}\text { Coeff/ } \\
\text { se }\end{array}$ & $p$ \\
\hline Depression & Gaze sad & .15 & $<1$ & $\mathrm{~ns}$ \\
Gaze sad & Depression & .36 & 2.15 & .032 \\
Depression & Gaze happy & .05 & $<1$ & $\mathrm{~ns}$ \\
Gaze happy & Depression & -.49 & 2.88 & .004 \\
Depression & Gaze neutral & .17 & $<1$ & $\mathrm{~ns}$ \\
Gaze neutral & Depression & .11 & $<1$ & $\mathrm{~ns}$ \\
Depression & Gaze angry & .08 & $<1$ & $\mathrm{~ns}$ \\
Gaze angry & Depression & -.15 & $<1$ & $\mathrm{~ns}$ \\
\hline
\end{tabular}

Coeff. represents standardized coefficients

changes in depressive symptoms. There was no evidence for a causal sequence in which changes in depressive symptoms lead to changes in attentional focus.

\section{Discussion}

Attentional biases are believed to play a key role in the onset, maintenance, and recurrence of depression (e.g., De Raedt and Koster 2010). Research has documented that attentional biases in depression consist of greater attention to negative information such as sad faces and a reduction in attention to positive stimuli such as happy faces (Armstrong and Olatunji 2012). In the current study, we evaluated the effectiveness of an 8-week MBCT training on modification of attentional biases to emotional faces in a sample of currently depressed individuals.

As expected, we found a significant decrease in CESD scores in the MBCT group, whereas there were no changes in the control group. This finding is consistent with the results of several studies that have shown that individuals who are currently depressed can benefit from MBCT (e.g., Van Aalderen et al. 2012), and it is consistent with the conclusions of meta-analyses showing the effectiveness of mindfulnessbased interventions (MBIs) in treating current depression (Goldberg et al. 2018; Strauss et al. 2014). Further, as expected, we found reduced gaze duration to negative faces, measured by a decrease in time spent viewing sad and angry faces for the MBCT group, whereas there were no such changes in the control group. Moreover, relative gaze time at happy faces significantly increased from pre- to post-training in MBCT group, and following MBCT individuals spent more time looking at happy faces than at angry and neutral faces.

These findings are consistent with how mindfulness and MBCT have been conceptualized. Mindfulness training teaches people to rely less on preconceived ideas, beliefs, and biases and to rely more on paying attention to all available information in the present moment (Bishop 2002). The enhancement of selective attention to attend to only one particular component of the present moment (such as breathing sensations) and the enhancement of sustained attention have been proposed as central practices in MBCT (Teasdale et al. 1995). They have also been proposed as essential elements of why mindfulness training changes people's thinking and increases their well-being (Holas and Jankowski 2013). MBCT emphasizes attentional training and a focus on participants' moment-to-moment experiences irrespective of affective valence or the presence of physical discomfort (Kocovski et al. 2015). This may help people to develop the ability to decenter from mental events such as negative thoughts or memories (Teasdale et al. 2002).

Surprisingly, very little work has been done to determine if MBCT leads to the modification of attentional biases to dysphoric information in current depression. The only published study of which we are aware that examined the effects of mindfulness training on attention to emotional faces (De Raedt et al. 2012) found that after MBCT, previously depressed individuals exhibited reduced facilitation of attention for negative faces. These findings were interpreted as indicating of an open attention toward all emotional information (De Raedt et al. 2012).

The results of the present study suggest more specific changes than those discussed by De Raedt et al., i.e., a general decrease in attention to negative faces and an increase to positive faces following MBCT. Our findings are consistent with the results of Verhoeven et al. (2014) who found that response times on an emotional Stroop task decreased after MBCT in the previously depressed. Such results suggest information related to depression may attract less attention following MBCT.

In addition to finding that MBCT led to changes in means of gaze duration and depressive symptoms among participants who received MBCT, we also found lagged relationships from gaze duration to depressive symptoms, whereas there were no significant lagged relationships from symptoms to gaze duration. Such a pattern is consistent with the assumption that changes in attentional focus lead to changes in depressive symptoms, or more broadly, with the assumption that attentional focus is more of a cause of depression (as posited by numerous theories and models, (e.g., Clark and Beck 1999; Koster et al. 2011) rather than a result of it.

Attentional improvement has been suggested as an important reason why MBCT is effective in depression in addition to change in mindfulness, rumination, worry, and selfcompassion which have been more frequently investigated for mediation effects (Alsubaie et al. 2017; van der Velden et al. 2015). Attentional improvement posits that improved abilities to regulate attention and to disengage from depressogenic cognition translate into better treatment outcomes (van der Velden et al. 2015). Within the context of 
MBCT, Van den Hurk et al. (2012) also intended to verify the assumption linking clinical improvements to improvements in the self-regulation of attention; however, they did not find support for this. One reason for this may be that Van den Hurk et al. examined changes in attentional processing to neutral, not emotional information, as we did in the current study, and a second reason may be the weaknesses of manual reaction time that Van den Hurk et al. used to measure attention.

\section{Limitations and Future Directions}

Although the present study generally met our expectations, there were some limitations. First, there was no follow-up assessment, so we cannot know if the changes we found were maintained over time. In addition, we examined a limited set of emotions. Although happiness and sadness are central to the experience of depression, it would be useful to study attention to other emotions such as fear. Finally, the causal relationship between attentional biases and symptoms should be examined in experimental settings that provide a better basis for drawing casual inferences and with larger samples that would provide more statistical power than we had.

Although MBCT has been shown to be effective, an important limitation of the majority of studies, including the present study, is the absence of an active control condition (ACC). The results of studies comparing MBCT to ACCs provide mixed support for the effectiveness of MBCT in terms of depressive relapse and related symptoms (e.g., Williams et al. 2014; Shallcross et al. 2015). In addition, several authors, including founders of MBCT (Segal et al. 2002), have warned that certain characteristics of depression, such as aversive content of depressive thoughts and feelings and ruminative processing, may make it difficult for depressed people to engaging in and benefit from mindfulness based interventions. Clearly, more randomized control trials with ACCs are needed to draw firmer conclusion about the efficacy of MBCT to treat current depression.

Current models of depression suggest that cognitive biases reflect regulatory deficits in attentional control (e.g., Joormann 2010; Koster et al. 2011), the ability to exert topdown control of attention. Future studies are needed to determine if MBCT not only modifies processing tendencies but also modifies dysfunctions in attentional control that may be responsible for negative interpretations of emotional information.

Author Contributions PH: designed and executed the study and was primarily responsible for writing the paper. IK: helped with the study design, conducted data analyses, and helped write the paper. KW: assisted with the data analyses and helped write the paper. MR: helped with the study design and data collection. JN: helped with the study design, data analysis, and writing of the paper. All authors approved the final version of the manuscript for submission.
Funding Information Support for this research was provided by the National Science Center, Harmonia Grant: 2012/04/M/HS6/00/470 to the 2nd author and Internal Grant (BST, no 0177700-41) of Psychology Faculty University of Warsaw to the 1st author.

\section{Compliance with Ethical Standards}

Conflict of Interest The authors declare that they have no conflict of interest.

Ethics Statement This study was approved by the institutional review board for research involving human subjects of SWPS University of Social Sciences and Humanities.

Informed Consent Statement Informed consent was obtained from all participants.

Open Access This article is licensed under a Creative Commons Attribution 4.0 International License, which permits use, sharing, adaptation, distribution and reproduction in any medium or format, as long as you give appropriate credit to the original author(s) and the source, provide a link to the Creative Commons licence, and indicate if changes were made. The images or other third party material in this article are included in the article's Creative Commons licence, unless indicated otherwise in a credit line to the material. If material is not included in the article's Creative Commons licence and your intended use is not permitted by statutory regulation or exceeds the permitted use, you will need to obtain permission directly from the copyright holder. To view a copy of this licence, visit http://creativecommons.org/licenses/by/4.0/.

\section{References}

Alsubaie, M., Abbott, R., Dunn, B., Dickens, C., Keil, T. F., Henley, W., \& Kuyken, W. (2017). Mechanisms of action in mindfulness-based cognitive therapy (MBCT) and mindfulness-based stress reduction (MBSR) in people with physical and/or psychological conditions: a systematic review. Clinical Psychology Review, 55, 74-91. https:// doi.org/10.1016/j.cpr.2017.04.008.

Anderson, N. D., Lau, M. A., Segal, Z. V., \& Bishop, S. R. (2007). Mindfulness-based stress reduction and attentional control. Clinical Psychology \& Psychotherapy: An International Journal of Theory \& Practice, 14(6), 449-463. https://doi.org/10.1002/cpp.544.

Armstrong, T., \& Olatunji, B. O. (2012). Eye tracking of attention in the affective disorders: a meta-analytic review and synthesis. Clinical Psychology Review, 32(8), 704-723. https://doi.org/10.1016/j.cpr. 2012.09.004.

Bar-Haim, Y., Lamy, D., Pergamin, L., Bakermans-Kranenburg, M. J., \& Van Ijzendoorn, M. H. (2007). Threat-related attentional bias in anxious and nonanxious individuals: a meta-analytic study. Psychological Bulletin, 133(1), 1. https://doi.org/10.1037/0033-2909.133.

Bishop, S. R. (2002). What do we really know about mindfulness-based stress reduction? Psychosomatic Medicine, 64(1), 71-83. https://doi. org/10.1097/00006842-200201000-00010.

Bishop, S. R., Lau, M., Shapiro, S., Carlson, L., Anderson, N. D., Carmody, J., et al. (2004). Mindfulness: a proposed operational definition. Clinical Psychology: Science and Practice, 11(3), 230-241. https://doi.org/10.1093/clipsy.bph077.

Caseras, X., Garner, M., Bradley, B. P., \& Mogg, K. (2007). Biases in visual orienting to negative and positive scenes in dysphoria: an eye movement study. Journal of Abnormal Psychology, 116(3), 491. https://doi.org/10.1037/0021-843X.116.3.491. 
Chambers, R., Lo, B. C. Y., \& Allen, N. B. (2008). The impact of intensive mindfulness training on attentional control, cognitive style, and affect. Cognitive Therapy and Research, 32(3), 303-322. https://doi. org/10.1007/s10608-007-9119-0.

Chan, D., \& Woollacott, M. (2007). Effects of level of meditation experience on attentional focus: is the efficiency of executive or orientation networks improved? The Journal of Alternative and Complementary Medicine, 13(6), 651-658. https://doi.org/10.1089/acm.2007.7022.

Clark, D. A., \& Beck, A. T. (1999). Scientific foundations of cognitive theory and therapy of depression. New York: John Wiley \& Sons.

Clasen, P. C., Wells, T. T., Ellis, A. J., \& Beevers, C. G. (2013). Attentional biases and the persistence of sad mood in major depressive disorder. Journal of Abnormal Psychology, 122(1), 74. https:// doi.org/10.1037/a0029211.

Cuijpers, P., van Straten, A., Bohlmeijer, E., Hollon, S. D., \& Andersson, G. (2010). The effects of psychotherapy for adult depression are overestimated: a meta-analysis of study quality and effect size. Psychological Medicine, 40(2), 211-223. https://doi.org/10.1017/ S0033291709006114.

De Raedt, R., \& Koster, E. H. (2010). Understanding vulnerability for depression from a cognitive neuroscience perspective: a reappraisal of attentional factors and a new conceptual framework. Cognitive, Affective, \& Behavioral Neuroscience, 10(1), 50-70. https://doi.org/ 10.3758/CABN.10.1.50.

De Raedt, R., Baert, S., Demeyer, I., Goeleven, E., Raes, A., Visser, A., et al. (2012). Changes in attentional processing of emotional information following mindfulness-based cognitive therapy in people with a history of depression: towards an open attention for all emotional experiences. Cognitive Therapy and Research, 36(6), 612620. https://doi.org/10.1007/s10608-011-9411-x.

Depression, W. H. O. (2017). Other common mental disorders: global health estimates (pp. 1-24). Geneva: World Health Organization.

Dimidjian, S., Hollon, S. D., Dobson, K. S., Schmaling, K. B., Kohlenberg, R. J., Addis, M. E., et al. (2006). Randomized trial of behavioral activation, cognitive therapy, and antidepressant medication in the acute treatment of adults with major depression. Journal of Consulting and Clinical Psychology, 74(4), 658. https://doi.org/ 10.1037/0022-006X.74.4.658.

Disner, S. G., Shumake, J. D., \& Beevers, C. G. (2017). Self-referential schemas and attentional bias predict severity and naturalistic course of depression symptoms. Cognition and Emotion, 31(4), 632-644. https://doi.org/10.1080/02699931.2016.1146123.

Donaldson, C., Lam, D., \& Mathews, A. (2007). Rumination and attention in major depression. Behaviour Research and Therapy, 45(11), 2664-2678. https://doi.org/10.1016/j.brat.2007.07.002.

Eizenman, M., Lawrence, H. Y., Grupp, L., Eizenman, E., Ellenbogen, M., Gemar, M., \& Levitan, R. D. (2003). A naturalistic visual scanning approach to assess selective attention in major depressive disorder. Psychiatry Research, 118(2), 117-128. https://doi.org/10. 1016/S0165-1781(03)00068-4.

Everaert, J., Duyck, W., \& Koster, E. H. (2014). Attention, interpretation, and memory biases in subclinical depression: a proof-of-principle test of the combined cognitive biases hypothesis. Emotion, 14(2), 331. https://doi.org/10.1037/a0035250.

Finucane, A., \& Mercer, S. W. (2006). An exploratory mixed methods study of the acceptability and effectiveness of mindfulness-based cognitive therapy for patients with active depression and anxiety in primary care. BMC Psychiatry, 6(1), 14. https://doi.org/10.1186/1471-244X-6-14.

Foland-Ross, L. C., \& Gotlib, I. H. (2012). Cognitive and neural aspects of information processing in major depressive disorder: an integrative perspective. Frontiers in Psychology, 3, 489. https://doi.org/10. 3389/fpsyg.2012.00489.

Godfrin, K. A., \& Van Heeringen, C. (2010). The effects of mindfulnessbased cognitive therapy on recurrence of depressive episodes, mental health and quality of life: a randomized controlled study.
Behaviour Research and Therapy, 48(8), 738-746. https://doi.org/ 10.1016/j.brat.2010.04.006.

Goeleven, E., De Raedt, R., Leyman, L., \& Verschuere, B. (2008). The Karolinska directed emotional faces: a validation study. Cognition and Emotion, 22(6), 1094-1118. https://doi.org/10.1080/ 02699930701626582.

Goldberg, S. B., Tucker, R. P., Greene, P. A., et al. (2018). Mindfulnessbased interventions for psychiatric disorders: a meta-analysis. Clinical Psychology Review, 59, 52-60. https://doi.org/10.1016/j. cpr.2017.10.011.

Gu, J., Strauss, C., Bond, R., \& Cavanagh, K. (2015). How do mindfulness-based cognitive therapy and mindfulness-based stress reduction improve mental health and wellbeing? A systematic review and meta-analysis of mediation studies. Clinical Psychology Review, 37, 1-12. https://doi.org/10.1016/j.cpr.2015.01.006.

Holas, P., \& Jankowski, T. (2013). A cognitive perspective on mindfulness. International Journal of Psychology, 48(3), 232-243. https:// doi.org/10.1080/00207594.2012.658056.

Holas, P., Krejtz, I., Rusanowska, M., Rohnka, N., \& Nezlek, J. B. (2019). Attention to negative words predicts daily rumination among people with clinical depression: evidence from an eye tracking and daily diary study. Cognition and Emotion, 33(6), 12771283. https://doi.org/10.1080/02699931.2018.1541168.

Jha, A. P., Krompinger, J., \& Baime, M. J. (2007). Mindfulness training modifies subsystems of attention. Cognitive, Affective, \& Behavioral Neuroscience, 7(2), 109-119. https://doi.org/10.3758/CABN.7.2.109.

Joormann, J. (2010). Cognitive inhibition and emotion regulation in depression. Current Directions in Psychological Science, 19(3), 161166. https://doi.org/10.1177/0963721410370293.

Joormann, J., \& Gotlib, I. H. (2007). Selective attention to emotional faces following recovery from depression. Journal of Abnormal Psychology, 116(1), 80. https://doi.org/10.1037/0021-843X.116.1.80.

Kabat-Zinn, J. (2003). Mindfulness-based interventions in context: past, present, and future. Clinical Psychology: Science and Practice, 10(2), 144-156. https://doi.org/10.1093/clipsy.bpg016.

Kellough, J. L., Beevers, C. G., Ellis, A. J., \& Wells, T. T. (2009). Time course of selective attention in clinically depressed young adults: an eye tracking study. Behaviour Research and Therapy, 46, 12381243. https://doi.org/10.1016/j.brat.2008.07.004.

Kenny, M. A., \& Williams, J. M. G. (2007). Treatment-resistant depressed patients show a good response to mindfulness-based cognitive therapy. Behaviour Research and Therapy, 45(3), 617-625. https://doi.org/10.1016/j.brat.2006.04.008.

Kessler, R. C., Berglund, P., Demler, O., Jin, R., Koretz, D., Merikangas, K. R., et al. (2003). The epidemiology of major depressive disorder: results from the National Comorbidity Survey Replication (NCS-R). Jama, 289(23), 3095-3105. https://doi.org/10.1001/jama.289.23.3095.

Kessler, R. C., Aguilar-Gaxiola, S., Alonso, J., Chatterji, S., Lee, S., Ormel, J., et al. (2009). The global burden of mental disorders: an update from the WHO World Mental Health (WMH) surveys. Epidemiology and Psychiatric Sciences, 18(1), 23-33.

Kocovski, N., Fleming, J., Hawley, L., Ho, M.-H. R., \& Antony, M. M. (2015). Mindfulness and acceptance-based group therapy and traditional cognitive behavioral group therapy for SAD. Behaviour Research and Therapy, 70, 11-22. https://doi.org/10.1016/j.brat. 2015.04.005.

Koster, E. H. W., De Lissnyder, E., Derakshan, N., \& De Raedt, R. (2011). Understanding depressive rumination from a cognitive science perspective: the impaired disengagement hypothesis. Clinical Psychology Review, 31(1), 138-145. https://doi.org/10.1016/j.cpr. 2010.08.005.

Krejtz, I., Holas, P., Rusanowska, M., \& Nezlek, J. B. (2018). Positive online attentional training as a means of modifying attentional and interpretational biases among the clinically depressed: an experimental study using eye tracking. Journal of Clinical Psychology, 74(9), 1594-1606. https://doi.org/10.1002/jclp.22617. 
Kupfer, D. J., Frank, E., \& Wamhoff, J. (1996). Mood disorders: update on prevention of recurrence. In C. Mundt, M. J. Goldstein, K. Hahlweg, P. Fiedler, et al. (Eds.), Interpersonal factors in the origin and course of affective disorders (pp. 289-302). Gaskell/Royal College of Psychiatrists.

Kuyken, W., Warren, F. C., Taylor, R. S., Whalley, B., Crane, C., Bondolfi, G., et al. (2016). Efficacy of mindfulness-based cognitive therapy in prevention of depressive relapse: an individual patient data meta-analysis from randomized trials. JAMA Psychiatry, 73(6), 565-574. https://doi.org/10.1001/jamapsychiatry.2016.0076.

Lau, H. C., Rogers, R. D., Haggard, P., \& Passingham, R. E. (2004). Attention to intention. Science, 303(5661), 1208-1210. https://doi. org/10.1126/science.1090973.

Lebois, L. A., Papies, E. K., Gopinath, K., Cabanban, R., Quigley, K. S., Krishnamurthy, V., et al. (2015). A shift in perspective: decentering through mindful attention to imagined stressful events. Neuropsychologia, 75, 505-524. https://doi.org/10.1016/j. neuropsychologia.2015.05.030.

Leyman, L., De Raedt, R., Vaeyens, R., \& Philippaerts, R. M. (2011). Attention for emotional facial expressions in dysphoria: an eyemovement registration study. Cognition and Emotion, 25(1), 111120. https://doi.org/10.1080/02699931003593827.

Ma, S. H., \& Teasdale, J. D. (2004). Mindfulness-based cognitive therapy for depression: replication and exploration of differential relapse prevention effects. Journal of Consulting and Clinical Psychology, 72(1), 31. https://doi.org/10.1037/0022-006X.72.1.31.

Moore, A., \& Malinowski, P. (2009). Meditation, mindfulness and cognitive flexibility. Consciousness and Cognition, 18(1), 176-186. https://doi.org/10.1016/J.CONCOG.2008.12.008.

Muthén, L. K., \& Muthén, B. O. (1998-2012). Mplus user's guide: statistical analysis with latent variables (7th ed.). Los Angeles: Muthén \& Muthén.

National Collaborating Centre for Mental Health. (2009). Depression: the treatment and management of depression in adults. (Clinical Guideline 90). NICE. (http://www.nice.org.uk/nicemedia/pdf/ CG90NICEguideline.pdf).

Owens, M., \& Gibb, B. E. (2017). Brooding rumination and attentional biases in currently non-depressed individuals: an eye-tracking study. Cognition and Emotion, 31(5), 1062-1069. https://doi.org/10.1080/ 02699931.2016.1187116.

Peckham, A. D., McHugh, R. K., \& Otto, M. W. (2010). A meta-analysis of the magnitude of biased attention in depression. Depression and Anxiety, 27(12), 1135-1142. https://doi.org/10.1002/da.20755.

Piet, J., \& Hougaard, E. (2011). The effect of mindfulness-based cognitive therapy for prevention of relapse in recurrent major depressive disorder: a systematic review and meta-analysis. Clinical Psychology Review, 31(6), 1032-1040. https://doi.org/10.1016/j.cpr.2011.05.002.

Radloff, L. S. (1977). The CES-D scale: a self-report depression scale for research in the general population. Applied Psychological Measurement, 1(3), 385-401. https://doi.org/10.1177/ 014662167700100306.

Segal, Z. V., Williams, J. M. G., \& Teasdale, J. D. (2002). Mindfulnessbased cognitive therapy for depression: a new approach to preventing relapse. New York: Guilford Press. https://doi.org/10. 1037/e533222009-006.

Segal, Z. V., Kennedy, S., Gemar, M., Hood, K., Pedersen, R., \& Buis, T. (2006). Cognitive reactivity to sad mood provocation and the prediction of depressive relapse. Archives of General Psychiatry, 63(7), 749-755. https://doi.org/10.1001/archpsyc.63.7.749.

Shallcross, A. J., Gross, J. J., Visvanathan, P. D., Kumar, N., Palfrey, A., Ford, B. Q., et al. (2015). Relapse prevention in major depressive disorder: mindfulness-based cognitive therapy versus an active control condition. Journal of Consulting and Clinical Psychology, 83(5), 964. https://doi.org/10.1037/ccp0000050.

Sheehan, D. V., Lecrubier, Y., Sheehan, K. H., Amorim, P., Janavs, J., Weiller, E., et al. (1998). The Mini-International Neuropsychiatric
Interview (M.I.N.I.): the development and validation of a structured diagnostic psychiatric interview for DSM-IV and ICD-10. The Journal of Clinical Psychiatry, 59(Suppl 20), 22-57.

Slagter, H. A., Lutz, A., Greischar, L. L., Francis, A. D., Nieuwenhuis, S., Davis, J. M., \& Davidson, R. J. (2007). Mental training affects distribution of limited brain resources. PLoS Biology, 5(6), e138. https://doi.org/10.1371/journal.pbio.0050138.

Strauss, C., Cavanagh, K., Oliver, A., et al. (2014). Mindfulness-based interventions for people diagnosed with a current episode of an anxiety or depressive disorder: a meta-analysis of randomised controlled trials. PloS one, 9(4), e96110. https://doi.org/10.1371/ journal.pone.0096110.

Teasdale, J. D., Segal, Z., Williams, J. M. G. (1995). How does cognitive therapy prevent depressive relapse and why should attentional control (mindfulness) training help? Behaviour Research and therapy, $33(1), 25-39$.

Teasdale, J. D., Segal, Z. V., Williams, J. M. G., Ridgeway, V. A., Soulsby, J. M., Lau, M. A. (2000). Prevention of relapse/ recurrence in major depression by mindfulness-based cognitive therapy. Journal of Consulting and Clinical Psychology, 68(4), 615. https://doi.org/10.1037/0022-006X.68.4.615.

Teasdale, J. D., Moore, R. G., Hayhurst, H., Pope, M., Williams, S., Segal, Z. V. (2002). Metacognitive awareness and prevention of relapse in depression: empirical evidence. Journal of Consulting and Clinical Psychology, 70(2), 275.

Van Aalderen, J. R., Donders, A. R. T., Giommi, F., Spinhoven, P., Barendregt, H. P., \& Speckens, A. E. M. (2012). The efficacy of mindfulness-based cognitive therapy in recurrent depressed patients with and without a current depressive episode: a randomized controlled trial. Psychological Medicine, 42(5), 989-1001. https://doi. org/10.1017/S0033291711002054.

van den Hurk, P. A., Giommi, F., Gielen, S. C., Speckens, A. E., \& Barendregt, H. P. (2010). Greater efficiency in attentional processing related to mindfulness meditation. Quarterly Journal of Experimental Psychology, 63(6), 1168-1180. https://doi.org/10. 1080/17470210903249365.

van den Hurk, P. A., van Aalderen, J. R., Giommi, F., Donders, R. A., Barendregt, H. P., \& Speckens, A. E. (2012). An investigation of the role of attention in mindfulness-based cognitive therapy for recurrently depressed patients. Journal of Experimental Psychopathology, 3(1), 103-120. https://doi.org/10.5127/jep.024811.

van der Velden, A. M., Kuyken, W., Wattar, U., Crane, C., Pallesen, K. J., Dahlgaard, J., et al. (2015). A systematic review of mechanisms of change in mindfulness-based cognitive therapy in the treatment of recurrent major depressive disorder. Clinical Psychology Review, 37, 26-39. https://doi.org/10.1016/j.cpr.2015.02.001.

Verhoeven, J. E., Vrijsen, J. N., van Oostrom, I., Speckens, A. E., \& Rinck, M. (2014). Attention effects of mindfulness-based cognitive therapy in formerly depressed patients. Journal of Experimental Psychopathology, 5(4), 414-424. https://doi.org/10.5127/jep.037513.

Williams, J. M. G., \& Kabat-Zinn, J. (2011). Mindfulness: diverse perspectives on its meaning, origins, and multiple applications at the intersection of science and dharma. Contemporary Buddhism, 12(01), 1-18. https://doi.org/10.1080/14639947.2011.564811.

Williams, J. M. G., Watts, F. N., MacLeod, C., Mathews, A. (1988). Cognitive psychology and emotional disorders. New York: John Wiley \& Sons.

Williams, J. M. G., Crane, C., Barnhofer, T., Brennan, K., Duggan, D. S., Fennell, M. J., et al. (2014). Mindfulness-based cognitive therapy for preventing relapse in recurrent depression: a randomized dismantling trial. Journal of Consulting and Clinical Psychology, 82(2), 275. https://doi.org/10.1037/a0035036.

Publisher's Note Springer Nature remains neutral with regard to jurisdictional claims in published maps and institutional affiliations. 